\section{YOUR ANNOUNCEMENT COULD APPEAR IN THIS SPOT!}

As a regular reader of the Canadian Journal of Anaesthesia you are aware of the high quality of our publication. High quality has translated into a large readership. At present, the CJA is sent to over 5,000 individuals and institutions across Canada, the United States and overseas, with a large hidden readership at major hospitals and medical libraries worldwide.

This is your monthly target audience for announcements covering:

Positions Available

Positions Wanted

Meetings

Postgraduate Courses

Other Events

Call our sales representatives for further details and to book space in the next available issue!

Canadian Journal of Anaesthesia c/o Keith Health Care Communications 1382 Hurontario Street

Mississauga, $\mathrm{ON}$

Canada

Phone: (905) 278-6700 Fax: (905) 278-4850

\section{ANAESTHETIST}

Peel Memorial Hospital has an immediate requirement for a certified Anaesthetist to join 10 other Anaesthetists. The candidate will have strong clinical skills and will have training and an interest in Paediatric Anaesthesia. Peel Memorial Hospital is a busy $300+$ bed community hospital situated in Brampton, approximately 35 minutes from Toronto.

Please send enquiries and curriculum vitae to:

\section{Dr, Andrew Scott}

Chief, Department of Anaesthesia

Peel Memorial Hospital, 20 Lynch St. Brampton, ON L6W $2 Z 8$

\title{
Opportunity in Anaesthesia Saint John, NB
}

The Atlantic Health Sciences Corporation is seeking two anaesthetists with training or experience in cardiac anaesthesia to join its department of 16. The successful candidate(s) will be based in Saint John, New Brunswick.

The Saint John Regional Hospital is a 500+ bed accredited tertiary facility which serves as provincial referral centre for several services such as, cardiac surgery, neurosurgery and reconstructive plastic surgery. Anaesthesia is provided for all surgical specialities. There is a comprehensive obstetrical anaesthesia service. The department is also involved in intensive care and pain management.

St. Joseph's, is a community hospital functioning as a day surgery and short stay surgery unit.

In addition to this varied clinical practice, the department is engaged in an active residency training programme affiliated with Dalhousie University. The successful candidate will be eligible for a university appointment.

Saint John serves a population of 125,000 and is Canada's first incorporated city. The beautiful St. John and Kennebecasis Rivers comprise the city's waterways and offer excellent conditions for boating and other outdoor activities. It is a great place to raise a family.

Candidates should be certified by the Royal College of Physicians and Surgeons of Canada. They should permanently reside in Canada. Post-certification training in cardiac anaesthesia is preferred (particularly in the area of transoesophageal echocardiography).

If you or a fellow anaesthetist are interested in being considered for these positions, I would very much like to hear from you

E. Colin Davies, MB,BCH,BAO, FRCP (C)

Clinical Department Head of Anaesthesia

Atlantic Health Sciences Corporation

P.O. Box 5200

Saint John, NB E2L 4L4 CANADA

(506) 648-6861 FAX: (506) 648-6860

Visit our Web Site w'ww.ahsc.health.nb.ca 